\title{
Erratum to: A systematic review of outcomes of chronic disease self-management interventions
}

\author{
Sandra Nolte $\cdot$ Richard H. Osborne
}

Published online: 27 November 2012

(C) Springer Science+Business Media Dordrecht 2012

\section{Erratum to: Qual Life Res}

DOI 10.1007/s11136-012-0302-8

Please note the below specified errors concerning reference numbers cited in the text of the original article.

Results section, 2nd paragraph, 4th sentence:

'.. back pain [46], chronic pain [47], and fibromyalgia [48] ...'

should read
'... back pain [46,47], chronic pain [48], and fibromyalgia [29] ...'

Appendix, Table 2, 1st column, 10th entry:

'Lorig et al. [19] (Spanish ASMP)' should read 'Lorig et al. [42] (Spanish ASMP)'

Appendix, Table 2, 1st column, 11th entry:

'Lorig et al. [16] (CDSMP)' should read 'Lorig et al. [19] (CDSMP)'

The online version of the original article can be found under doi:10.1007/s11136-012-0302-8.

S. Nolte $(\bowtie)$

Medical Clinic for Psychosomatics, Charité, University

Medicine Berlin, Luisenstraße 13a, 10117 Berlin, Germany

e-mail: sandra.nolte@charite.de

\section{S. Nolte · R. H. Osborne}

Public Health Innovation, Population Health Strategic Research

Centre, School of Health and Social Development, Faculty of

Health, Deakin University, Burwood, VIC, Australia 